\title{
A systematic mapping protocol: what are the impacts of different upstream business models in the agriculture and forestry sector on sustainable development in tropical developing countries?
}

\author{
George Schoneveld1*, Filipe Di Matteo ${ }^{1,2}$, Frederico Brandao ${ }^{1,2}$, Pablo Pacheco ${ }^{1}$, Idsert Jelsma ${ }^{1,2}$ \\ and Eileen Dyer Jarnholt ${ }^{1,2,3}$
}

\begin{abstract}
Background: As a result of rising global food and energy insecurity, investors are increasingly seeking new opportunities in tropical developing countries endowed with comparatively cheap and abundant land resources. Predominantly targeting the agriculture and forestry sectors, these investments could make valuable contributions to the economies of developing countries. However, with most investors opting for plantation-oriented business models, in the context of weak governance regimes within many host countries, many fear that these investments may instead exacerbate socio-economic vulnerabilities and processes of environmental degradation. Therefore, there is a need to explore alternative upstream business models that are more inclusive of the poor and are more aligned with emergent green growth objectives. This systematic map aims to contribute to this debate by cataloging empirical studies conducted on the sustainability of different upstream business models in the agriculture and forestry sector (e.g. involving the cultivation of raw materials). The mapping will offer an overview of the type and quantity of research conducted to date, remaining knowledge gaps, and areas warranting a systematic review.
\end{abstract}

Methods: Searches will be conducted of both academic and grey literature by employing search strings that have been iteratively tested for comprehensiveness. Studies retrieved in the searches will be screened using pre-defined inclusion criteria and coded across a broad range of study characteristics. Inclusion criteria include, for example, type of business model employed, social, economic, and environmental impacts, and study design (e.g. generation of new empirical evidence). The outputs will be a database of included search results and a systematic map offering descriptive statistics and narrative assessment of the state of the evidence base in this topic.

Keywords: Agriculture, Business Models, Development, Equity, Poverty alleviation, Sustainability

\section{Background}

The confluence of the food and energy crises of the mid 2000s has revealed structural global issues related to long-term food and energy supplies and security [1,2]. In the context of a rapidly growing global population, changing consumption patterns, finite fossil fuel supplies, and climate change, security of access to natural resources to produce essential goods such as food and energy is becoming an economic imperative [3-5].

\footnotetext{
* Correspondence: g.schoneveld@cgiar.org

${ }^{1}$ Center for International Forestry Research (CIFOR), P.O. Box 0113 BOCBD,

Bogor 16000, Indonesia

Full list of author information is available at the end of the article
}

Countries with insufficient supplies of natural resources, but with sufficient capital are therefore increasingly encouraged to secure access to these resources beyond national boundaries. As the geographies of supply and demand become more distinct, the private sector is increasingly positioning itself to capitalise on the trade opportunities this creates (e.g. by gaining control over upstream value chain activities). As a result, recent years have witnessed an unprecedented surge in demand for large areas of farmland for the production of food crops and biofuel feedstocks especially in tropical developing countries, where fertile farmlands are comparatively cheap and abundant. 
However, because governments in most major investment destinations are ill equipped or are disinclined to adequately regulate farmland investments, in practice few sufficiently effective checks and balances are placed on land use change to plantation agriculture or forestry [6-8]. Evidence has shown that this could lead to a loss of biodiversity and forest cover [6,9-11], in turn detracting from the potential contribution of, for example, biofuels to improving the carbon balance. Additionally, as a result of inadequate statutory protection of customary tenure systems, traditional livelihood activities could be displaced without adequate redress, which in turn could adversely impact on the food and income insecurity of vulnerable societal groups [12-14].

These issues raise questions about particularly the social and environmental viability of business models that produce raw material through large-scale plantations. Many of these investments, therefore, fail to adequately address the three pillars of sustainable development, namely economic growth, environmental stewardship, and social inclusion. Many argue that long-term global food and energy security challenges could also be addressed through more smallholder-oriented development pathways $[15,16]$. This requires promotion of inclusive business models - seen here as business models that improve the livelihoods of low-income communities by integrating these into value chains as suppliers, employees, distributors, and consumers of goods and services [17]. Within the upstream agricultural and forestry sector, this includes such models as joint ventures, management contracts, and tenant and contract farming schemes [16]. Upstream business models are those business models applied to upstream value chain activities, which in this context involves cultivation of crops. The sustainability of such business models subsequently depends on their long-term economic viability and ability to assimilate green growth strategies (e.g. 'climate-smart' and 'low emission' agriculture). This topic is particularly relevant in light of global deregulation and liberalization processes that are increasingly relying on commodity markets to address global food and energy supply deficits and private sector investment to achieve poverty alleviation and green growth objectives [18-20].

Important questions, however, remain on the merits and demerits of the different dominant upstream business models. As noted by Kramer and Herrndorf [20], for example, while inclusiveness and green growth are mutually supporting objectives, in practice short-term trade-offs tend to generate tensions between inclusive and green business models. Some also warn that inclusive business models such as outgrower and tenant farming schemes could concentrate production risks with smallholders, engender land conflicts, and promote socioeconomic differentiation [21,22]. Furthermore there are positive examples of industrial plantations, which show that increased access to rural waged labor can contribute to female (economic) empowerment and benefit in particular the poorest, often landless, rural population [23]. In some situations, there are also clear economic advantages to large farms; for example, due to their greater ability to spread risks, adapt to market changes, internalize new innovations, and benefit from economies of scale [2]. Therefore, in order to design appropriate policy interventions and promote a more evidence-based debate, there is an urgent need to systematically evaluate different upstream business models, the conditions under which these can contribute to sustainable development, and the extent to which certain business models consistently outperform others on different sustainability dimensions. This requires an improved understanding of the relationship between context, business models, and social, economic, and environmental outcomes, as conceptualized in Figure 1. Since the rural population is often highly heterogeneous and distribution of impacts uneven, this also requires disaggregation by stakeholder group.

\section{Objective of the review}

For this review, we will produce a systematic map, which involves implementing a robust, repeatable, and transparent method for identifying and categorizing literature on broad research questions (such as this) [24]. Like the systematic review, a systematic map uses a comprehensive search strategy and applies clearly stated a-priori criteria for inclusion or exclusion of literature located during the search $[25,26]$. It however does not analyse, quantify and compare literature findings as is done in a Systematic Review, but rather describes the nature of the existing evidence base.

This systematic map will identify and categorize empirical studies that have been conducted on the social, economic, and environmental outcomes of upstream business models within the agricultural and forestry sector. It will go on to highlight inter alia the extent to which these studies capture the conditions shaping each outcome, variations in outcomes between stakeholder groups, and differences across business models. Besides creating an overview of the state of the art, the systematic map also serves to identify potential knowledge gaps and specific sub-topics for which available literature warrants a systematic review.

Through a meeting under the project "Large-Scale Investments in Food, Feed, and Energy (LIFFE Options)", the following research questions were identified to guide the systematic mapping:

\section{Primary research question}

- What types of sustainability impacts of different upstream business models in the agriculture and 


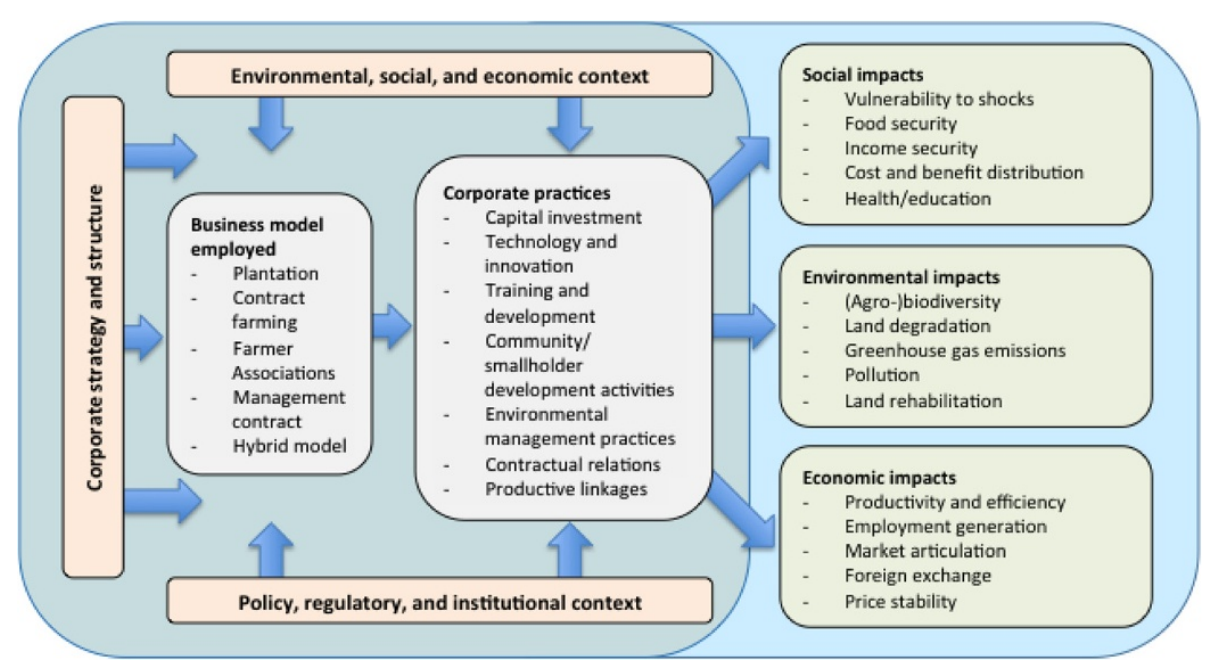

Figure 1 Conceptual framework for reviewing sustainability outcomes of upstream business models.

forestry sector have been documented in tropical developing countries? Deconstructed in Table 1.

\section{Secondary research questions}

- To what extent does the literature capture the conditions under which upstream business models impact on sustainable development?

- To what extent does the literature disaggregate outcomes by stakeholder group?

- To what extent does the literature compare outcomes between upstream business models?

Since the current debate is focused largely on risks and opportunities related to (transboundary) investment flows to developing country agriculture and forestry, this mapping is interested only in 'business models for investment'. This implies that it intends to catalogue only literature that relates to investments made directly by 'corporate entities' into the upstream production of raw materials, which can be private, public, or a combination of both. The entity would need to have a commercial orientation, where the primary objective is profit generation and relying on economies of scale and hired (as opposed to household) labour. However, it will not capture traditional public investments in, for example, input subsidies, extension services, or credit facilities.

\section{Methods}

Methods used in the development of the systematic map are adapted from the Collaboration for Environmental Evidence (CEE) systematic review guidelines [24], other systematic map protocols [26-28], and the Social Care Institute for Excellence (SCIE) systematic mapping guidance $[25,29,30]$.

\section{Search terms}

The search will, for practical reasons, be conducted in English only. However, search results in other languages will be incorporated into the systematic map, using online translation tools where necessary. Appropriate search terms and strings were tested using ISI Web of Science and Scopus. Searches were developed iteratively, relying on number of search results and the inclusion of reference publications. A short-list of 12 publications providing empirical evidence on a topic relevant to the subject area were used to determine comprehensiveness of the search terms and strings (see Additional file 1 for publication list and results). Since some articles are available in full-text form within some publication databases and some only in abstract form, searches apply only to articles' title, key words, and abstracts to prevent inconsistencies.

The scoping exercise revealed the complexity of researching broad, multi-disciplinary topics such as these. For example, in relation to the exposure terms,

Table 1 Elements of the primary systematic map research question

\begin{tabular}{llll}
\hline Population & Exposure & Comparators & Outcomes \\
\hline $\begin{array}{lll}\text { Ecosystems and local stakeholders impacted } \\
\text { by upstream business models }\end{array}$ & $\begin{array}{l}\text { Upstream business } \\
\text { models }\end{array}$ & $\begin{array}{l}\text { Other types of upstream business } \\
\text { models/without intervention, }\end{array}$ & $\begin{array}{l}\text { All outcomes related to the local distribution } \\
\text { of costs and benefits, economic viability, } \\
\text { before-after }\end{array}$ \\
\hline
\end{tabular}


umbrella terms such as 'business model' or 'inclusive business' are rarely used in the agriculture and forestry sector, there are often numerous synonymous terms (e.g. plantation, commercial farm, agribusiness), or interventions are not consistently labelled or categorized (e.g. tenant farming or management contract). Additionally, some abstracts do not explicitly refer to the sector; instead mentioning only the focal crop or commodity. Similarly, many articles explored very specific outcomes, with many articles not making explicit reference to outcome categories (e.g. 'social', 'economic', or 'environmental'). In order to ensure relevant literature is adequately captured, the following adjustments were made to the search string:

- The addition of more general exposure terms such as 'company', 'investment', and 'corporation' and prominent investment crops such as 'oil palm', 'sugarcane', and 'rubber' (based on number of hits).

- The addition of more specific outcome terms such as 'deforestation,' 'degradation', 'food security', and 'income'. Since it appeared that some articles failed to specify the types of outcomes researched in their abstracts, terms such as 'impacts, 'implications' and 'effects' were also included.

- The introduction of topical limiters. Where possible, searches are refined according to their research area; for example, 'Agriculture, 'Environmental Sciences' and 'Geography' are included, while 'Cell Biology' and 'Computer Sciences' are excluded. The testing revealed large numbers of results from unrelated research domains. The application of topical limiters significantly reduced this number, while continuing to capture the reference literature.

- The introduction of geographic limiters. An additional search string is used to confine results to 'tropical developing countries'. This includes all countries located between the Tropic of Cancer and Tropic of Capricorn and classified as 'developing' by the International Monetary Fund (IMF). Although it would have been useful to document literature from other regions also, since almost 25,000 search results were returned in Scopus, the geographic scope needed to be refined in order to obtain a more manageable number of search results. Although the inclusion of these limiters may lead to the exclusion of relevant literature - for example, since some abstracts and keywords neglect to specify their geographic scope - no such cases could be identified through the testing of search strings.

Table 2 provides an overview of the finalized search strings and the number of hits returned by Web of Science and Scopus for the different string combinations and with and without geographic and topical limiters. Additional file 2 provides an overview of the topical and geographic limiters that were applied in the testing of search terms and strings. These limiters will also be applied in the systematic map.

\section{Databases}

The search will cover the four online search databases listed below. These best represent the research areas relevant to the research questions. All bibliographical details retrieved by the search strategy, including abstracts, will be exported to bibliographical software such as Endnote. Duplicate results will be removed.

- AGRIS

- CAB Abstracts

- ISI Web of Science

- Scopus

\section{Internet search engine}

Since a large body of research is available as grey literature, the search will also utilize internet search engines. Applying modified search strings if necessary, the first 150 hits from each search engine (sorted by relevance) will be considered.

- Dogpile

- Google Scholar

- Scirus

\section{Other sources of grey literature}

Further grey literature searches will be conducted within databases of specialist institutions involved in research on relevant topics. These include:

- Center for International Forestry Research

- Food and Agriculture Organization of the United Nations

- International Food Policy Research Institute

- International Institute for Environment and Development

- OECD Development Center

- World Agroforestry Center

- World Bank

- World Resources Institute

\section{Search comprehensiveness assessment}

A preliminary assessment of the comprehensiveness of the search strategy was conducted during the scoping exercise. The iterative process of adding different search terms and ensuring search strings captured the reference literature appears to have ensured a sufficiently comprehensive search strategy: the final search strings located all of the 12 reference articles used to test search 
Table 2 Results by search string (performed on 5 May, 2014)

\begin{tabular}{|c|c|c|c|c|c|}
\hline \multirow{2}{*}{$\begin{array}{l}\text { Type of search } \\
\text { term }\end{array}$} & \multirow[t]{2}{*}{ Search string } & \multicolumn{2}{|c|}{ Web of Science } & \multicolumn{2}{|c|}{ Scopus } \\
\hline & & $\begin{array}{c}\text { With } \\
\text { limiters }\end{array}$ & $\begin{array}{l}\text { Without } \\
\text { limiters }\end{array}$ & $\begin{array}{l}\text { With } \\
\text { limiters }\end{array}$ & $\begin{array}{l}\text { Without } \\
\text { limiters }\end{array}$ \\
\hline Exposure & $\begin{array}{l}\text { (“"inclusive business" OR "business model" OR plantation OR outgrower OR } \\
\text { "tenant farm*" OR "management contract" OR "joint venture" OR "contract farm*" } \\
\text { OR cooperative OR "commercial farm*" OR agribusiness OR company OR } \\
\text { companies OR corporation OR investment OR investor) AND (agricultur* } \\
\text { OR forest* OR biofuel OR "oil palm" or sugarcane OR cotton OR rubber } \\
\text { OR maize OR rice OR cereal OR jatropha OR tobacco OR soy OR eucalyptus)) }\end{array}$ & 7,018 & 29,775 & 14,083 & 58,228 \\
\hline Outcome & $\begin{array}{l}\text { AND (impact OR implications OR benefit OR costs OR effect OR income OR } \\
\text { employ* OR livelihood OR deforest* OR degrad* OR conflict OR "food securit*" } \\
\text { OR "energy securit*" OR dispute OR equit* OR labor OR social OR poverty OR } \\
\text { "socio-economic" OR differentiation OR economic OR productivity OR yield OR } \\
\text { profit* OR viabilit* or environment* OR rights OR conservation) }\end{array}$ & 5,937 & 23,391 & 11,300 & 41,326 \\
\hline Population & $\begin{array}{l}\text { AND ("agricult* land" OR smallholder OR biodivers* OR forest OR environment } \\
\text { OR ecosystem OR "degraded land" OR women OR migrant OR wetland OR water } \\
\text { OR "land user" OR "affected persons" OR communit* OR farmer OR employee OR } \\
\text { household OR female OR peasant) }\end{array}$ & 4,965 & 17,762 & 8,657 & 28,161 \\
\hline
\end{tabular}

*Denotes a wildcard character.

comprehensiveness (Additional file 1). Although this has significantly widened the scope of the search and may lead to the inclusion of large numbers of irrelevant results, it will enhance the probability that most relevant articles are included.

However, there is a risk that some studies are not adequately captured through conventional channels (e.g. conference proceedings, unpublished manuscripts, internal working papers). We will aim to identify these by using our established networks of academics and other stakeholders with expertise in the field and solicit inputs from experts through social media (e.g. Academia, Research Gate, Twitter, and LinkedIn). Dedicated searches will also be conducted to identify appropriate papers hosted on conference websites and academic theses hosted on university repositories.

\section{Study inclusion criteria}

In order to warrant inclusion, each paper will have to conform to the following criteria:

- Relevant population: Studies should evaluate outcomes of business models on either the environment or on the human population within tropical developing countries.

- Relevant intervention/exposure: Studies will focus on one or more business models for investment in the agricultural, biofuel, and forestry sector in tropical developing countries. This will typically include, but may not be limited to, outgrower schemes, tenant farming schemes, nucleus-plasma schemes,

farmer-owned businesses, joint ventures, management contracts, and plantations. Logging concessions will be excluded from the analysis since these involve extraction, not production of raw materials. Agricultural business models that do not directly involve corporate entities are not be the object of analysis, though may be used as a comparator.

- Relevant outcomes: Studies should evaluate the different business models against measures of 'sustainability'. This ranges from economic (e.g. productivity and profitability gains) to social (e.g. equity, conflict, and wellbeing) and environmental indicators (e.g. deforestation, degradation, and pollution).

- Relevant study design: Studies should offer new empirical evidence, regardless of whether this is quantitative, qualitative, or mixed. Literature reviews, conceptualizations, and opinion pieces are excluded from the review, as are projections and scenario models.

- Relevant timeframe: In order to best capture contemporary processes and political and economic realities, studies should relate to interventions in the post-World War II era $(1945$ - 2014). This will, for example, exclude tenant farming schemes that dominated in feudalist and colonial societies.

Studies will be assessed for inclusion through a multitiered process: first, on the basis of title, then by abstract, and finally by full-text review. If insufficient information is available to evaluate whether inclusion is warranted (for example, during the title assessment phase), then it is included for the next phase. Where full-texts are not available, authors will be contacted directly.

The inclusion screening will be conducted by at least two reviewers that each will be responsible for their own set of literature. In order to test the consistency and objectivity of reviewer inclusion decisions, a Kappa analysis will first be conducted on 100 titles and abstracts, as per CEE (2013) guidelines. If a Kappa test returns a value 
Table 3 Data extraction and coding schema

\begin{tabular}{|c|c|}
\hline Variable & Key words/entry options \\
\hline Author(s) & Name \\
\hline Title & Name \\
\hline Date & Date \\
\hline Publisher & Name and location \\
\hline Volume, issue, page number & Number \\
\hline Publication type & $\begin{array}{l}\text { e.g. peer-reviewed journal article, } \\
\text { non peer-reviewed journal article, } \\
\text { conference paper, working paper, } \\
\text { thesis, book, book chapter }\end{array}$ \\
\hline Study year(s) & Year \\
\hline Study length & $\begin{array}{l}\text { Number of days/weeks/months/ } \\
\text { years }\end{array}$ \\
\hline Study country & Name \\
\hline Study design & $\begin{array}{l}\text { Experimental, quasi-experimental, } \\
\text { observational }\end{array}$ \\
\hline Data type & Quantitative, qualitative \\
\hline Data sources & Primary, secondary \\
\hline Research methods & $\begin{array}{l}\text { e.g. household survey, focus group } \\
\text { discussions, key informant } \\
\text { interviews, participatory research } \\
\text { methods, biodiversity assessment, } \\
\text { land use change analysis, value } \\
\text { chain analysis }\end{array}$ \\
\hline
\end{tabular}

Type of intervention(s) assessed e.g. outgrower, tenant farming, farmer-owned business, joint venture, management contract, plantation, other (specify)

Number of interventions assessed Number

Type of investor

Origin of investor

Unit of analysis

Sample size

Type of local social outcomes assessed

Type of economic outcomes assessed

Type of environmental outcomes assessed

Trade-offs between outcomes assessed

Types of stakeholders
Table 3 Data extraction and coding schema (Continued)

\begin{tabular}{|c|c|}
\hline Influence of external intervention & $\begin{array}{l}\text { e.g. none, voluntary certification } \\
\text { scheme, government program, } \\
\text { government regulation, trade } \\
\text { standard }\end{array}$ \\
\hline Type of contextual analysis & $\begin{array}{l}\text { e.g. none, legal, institutional, } \\
\text { geographic, socio-cultural, } \\
\text { economic }\end{array}$ \\
\hline $\begin{array}{l}\text { Linkages between intervention, } \\
\text { outcomes, and context explored } \\
\text { empirically }\end{array}$ & Yes, no \\
\hline Outcome determinants assessed & Yes, no \\
\hline Type of comparator & $\begin{array}{l}\text { e.g. none, temporal, other business } \\
\text { models, without intervention, } \\
\text { control groups }\end{array}$ \\
\hline Validity assessment & None, internal, external, both \\
\hline Intervention sampling strategy & $\begin{array}{l}\text { e.g. None specified, random, } \\
\text { stratified, systematic, cluster, } \\
\text { convenience, purposive, snow-ball }\end{array}$ \\
\hline Population sampling strategy & $\begin{array}{l}\text { e.g. None specified, random, } \\
\text { stratified, systematic, cluster, } \\
\text { convenience, purposive, snow-ball }\end{array}$ \\
\hline $\begin{array}{l}\text { Ex ante identification of relevant } \\
\text { stakeholder groups/ population } \\
\text { sub-groups for impact assessment }\end{array}$ & $\begin{array}{l}\text { Yes (and all captured separately } \\
\text { in research), yes (but only select } \\
\text { groups researched), no, not } \\
\text { specified }\end{array}$ \\
\hline Additional remarks & $\begin{array}{l}\text { Any additional notes on the paper } \\
\text { (e.g. potential biases) }\end{array}$ \\
\hline
\end{tabular}

lower than 0.6, reviewers will evaluate differences in the application of inclusion criteria and agree on corrective actions. The test will subsequently be conducted again, until an acceptable score is achieved. Any remaining disagreements over the relevance of articles will be resolved by a third reviewer. Studies read at the full-text stage but subsequently excluded will be recorded in supplementary materials, with the reasons for exclusion noted.

\section{Effect modifiers}

Differences in outcomes may be observed due to the differences in research methods, temporal and spatial scales, socio-economic, cultural, environmental, and governance context, crop and sectoral focus, marketorientation, and land tenure systems, all of which will be coded for each study.

\section{Study quality assessment}

This systematic map will not present full quality assessment. It will, however, code a number of indicators that will enable assessment of methodological rigor in the included studies, as is further detailed in the data extraction strategy (Table 3).

\section{Data extraction strategy}

Data from papers that remain following the inclusion and exclusion exercise will be extracted and coded, as 
per variables listed in Table 3. Data will be recorded in a Microsoft Excel spreadsheet. The spreadsheet will be divided into two sets - one will be a shortened version containing data from papers that are not accessible in full-text form and the other will contain data from fulltext analysis. Data extraction will be undertaken by at least two reviewers and will involve a Kappa test (using the procedure detailed under 'study inclusion criteria').

\section{Data mapping and presentation}

The systematic map will contain narrative and descriptive statistics, relating predominantly to quantity of relevant literature, by methods employed, geographic distribution, and types of interventions, outcomes, and populations analyzed. It will highlight the types of processes that shape sustainability outcomes, in line with the Conceptual Framework. It will also explore research gaps and topics warranting further systematic review (if any). A searchable Microsoft Access database of included full-text articles will be made available alongside the map.

\section{Additional files}

Additional file 1: Reference Literature and Search Results.

Additional file 2: Limiters included in search strategy.

\section{Competing interests}

There are no potential competing interests. This systematic map is funded by CIFOR through the DFID KNOW-FOR programme.

\section{Authors' contribution}

GS, PP, FM, FB, IJ, and ID conceived the research question. GS tested the search strings and drafted the manuscript. PP, FM, FB, IJ, and ID reviewed and commented on the manuscript. All authors read and approved the final manuscript.

\section{Author details}

${ }^{1}$ Center for International Forestry Research (CIFOR), P.O. Box 0113 BOCBD, Bogor 16000, Indonesia. 'Department of International Development Studies, Utrecht University (UU), Postbus 801253508 TC Utrecht, The Netherlands. ${ }^{3}$ Department of Society and Globalization, Roskilde University (RUC), Universitetsvej 1, 4000 Roskilde, Denmark.

Received: 8 May 2014 Accepted: 18 November 2014 Published: 10 March 2015

\section{References}

1. McMichael P. The land grab and corporate food regime restructuring. J Peasant Stud. 2012;39(3-4):681-701.

2. Deininger $K$, Byerlee $D$. The rise of large farms in land abundant countries: do they have a future? World Dev. 2012:40(4):701-14.

3. von Braun J, Meinzen-Dick R. 'Land grabbing' by Foreign Investors in Developing Countries: Risks and Opportunities, Policy Brief. Washington DC: International Food Policy Research Institute; 2009.

4. Zoomers A. Globalisation and the foreignisation of space: seven processes driving the current global land grab. J Peasant Stud. 2010;37(2):429-47.

5. de Schutter O. How not to think of land-grabbing: three critiques of large-scale investments in farmland. J Peasant Stud. 2011:38(2):249-79.

6. Schoneveld GC. The Governance of Large-Scale Farmland Investments in sub-Saharan Africa: A Comparative Analysis of the Challenges for Sustainability. Delft: Eburon Publishers; 2013.
7. German LA, Schoneveld GC, Mwangi E. Contemporary processes of largescale land acquisition in Sub-Saharan Africa: legal failures, or elite capture of the rule of law? World Dev. 2013;48:1-18.

8. Gordon-Maclean A, Laizer J, Harrison P, Shemdoe R. Biofuel Industry Study, Tanzania: An Assessment of the Current Situation. Dar-es-Salaam: World Wide Fund for Nature; 2009.

9. Nhantumbo I, Salomão A. Biofuels, Land Access and Rural Livelihoods in Mozambique. International Institute for Environment and Development and Centro Terra Viva: London and Maputo; 2010.

10. Rahmato D. Land to Investors: Large-Scale Land Transfers in Ethiopia. Forum for Social Studies: Addis Ababa; 2011.

11. Nguiffo S, Schwartz B. Herakles' 13th Labour? A Study of SGSOC's Land Concession in South-West Cameroon. Yaoundé: Centre pour L'Environnement et le Developpement; 2012

12. Schoneveld GC, German LA, Nukator ED. Land-based investments for rural development? A grounded analysis of the local impacts of biofuel feedstock plantations in Ghana. Ecol Soc. 2011;16(4):10.

13. Tsikata D, Yaro J. Land Market Liberalization and Trans-National Commercial Land Deals in Ghana Since the 1990s, Paper presented at the International Conference of Global Land Grabbing, 6-8 April 2011. Brighton: University of Sussex; 2012.

14. Shete M. Impact of Large Scale Agricultural Investment on Income and Food Security in Oromiya Region, Ethiopia. In: Paper Presented at Presentation at the Annual World Bank Conference On Land And Poverty, April 8-11. Washington DC: World Bank; 2013.

15. Sulle E, Hall R, Paradza G. Inclusive Business Models in Agriculture? Learning from Smallholder Cane Growers in Mozambique. Policy Brief 66. Brighton: Future Agricultures Consortium; 2014. Dummy Reference list.

16. Vermeulen S, Cotula L. Making the Most of Agricultural Investment: A Survey of Business Models That Provide Opportunities for Smallholders. London: International Institute for Environment and Development; 2010.

17. WBCSD and SNV. Inclusive Business: Creating Value in Latin America. WBCSD and SNV: Geneva and The Haque; 2011.

18. Asiedu E. Policy reform and foreign direct investment to Africa: absolute progress but relative decline. Dev Policy Rev. 2004;21(1):41-8.

19. Dupasquier C, Osakwe P. FDI in Africa: Performance, challenges, and responsibilities. J Asian Economies. 2005:17(2):241-60.

20. Herrndorf M, Krämer A. Policy Measures to Support Inclusive and Green Business Models. Geneva: DCED and United Nations; 2012.

21. Glover D, Kusterer K. Small Farmers, big Business: Contract Farming and Rural Development. London: Macmillan; 1990.

22. Porter G, Phillips-Howard K. Comparing contracts: an evaluation of contract farming schemes in Africa. World Dev. 1997;25(2):227-38.

23. Cramer C, Oya C, Sender J. Lifting the blinkers: a new view of power, diversity and poverty in Mozambican rural labour markets. J Mod Afr Stud. 2008;46(03):361-92.

24. Collaboration of Environmental Evidence (CEE). Systematic Review Guidelines Version 4.2. [http://www.environmentalevidence.org/Documents/ Guidelines.pdf]

25. Clapton J, Rutter D, Sharif N. SCIE Systematic Mapping Guidance. London: Social Care Institute for Excellence; 2009

26. Randall NP, James KL. The effectiveness of integrated farm management, organic farming and agri-environment schemes for conserving biodiversity in temperate Europe - A systematic map. Environ Evid. 2012;1(4):1-21.

27. Haddaway N, Styles D, Pullin AS. Environmental impacts of farm land abandonment in high altitude/mountain regions: a systematic map of the evidence. Environ Evid. 2013:2(18):1-18.

28. Roe D, Sandbrook C, Fancourt M, Schulte B, Munroe R, Sibanda M. A systematic map protocol: which components or attributes of biodiversity affect which dimensions of poverty? Environ Evid. 2013;2(1):1-8.

29. Bates S, Coren E. The Extent and Impact of Parental Mental Health Problems on Families and the Acceptability, Accessibility and Effectiveness of Interventions. London: Social Care Institute for Excellence; 2006.

30. Social Care Institute for Excellence (SCIE). SCIE Systematic Mapping Guidance. [http://www.scie.org.uk/publications/researchresources/rr03.pdf]

doi:10.1186/2047-2382-4-1

Cite this article as: Schoneveld et al:: A systematic mapping protocol: what are the impacts of different upstream business models in the agriculture and forestry sector on sustainable development in tropical developing countries?. Environmental Evidence 2015 3:1. 